\title{
PENGGUNAAN BATUBARA SEBAGAI PENGGANTI KEROSIN UNTUK MENGHEMAT BIAYA PRODUKSI CAMPURAN ASPAL PANAS
}

\author{
Yunan Hanun ${ }^{1}$ \\ Wegie Ruslan ${ }^{2}$ \\ Dosen Teknik Mesin STT Jakarta ${ }^{1}$, Alumni Teknik Mesin STT Jakarta ${ }^{2}$ \\ Jl. Proklamasi No. 27, Jakarta ${ }^{1,2}$ \\ Email: yunanhanun29@gmail.com ${ }^{l}$
}

\begin{abstract}
ABSTRAK
Studi ini bertujuan untuk mendukung program pemerintah sesuai dengan Peraturan Presiden no. 5 tahun 2006 tentang sasaran energi jangka panjang Indonesia tahun 2000-2025, yang tujuannya mencari dan menggunakan energi alternatif lain, yaitu, coal, gas, hydro, geothermal, biomass, angin, surya dan nuklir. Selama ini mesin pembuat campuran aspal panas (Asphalt Mixer Plant) menggunakan kerosin sebagai bahan bakar untuk memanaskan batu pecah, abu batu dan pasir sebelum dicampur dengan aspal semen. Permasalahan yang dihadapi selama ini adalah sampai dengan saat ini ketersediaan bahan bakar kerosin semakin sulit diperoleh dan harganya semakin tinggi. Sehingga biaya produksi menjadi tidak effisien lagi dan waktu penyelesaian pekerjaan (proyek) sering tidak sesuai rencana. Dari hasil penelitian, batubara dapat digunakan sebagai pengganti kerosin untuk membakar agregat pada Alat pembuat campuran aspal panas (Asphalt Mixer Plant) dengan cara mengganti burner kerosin dengan burner batubara. Dari segi biaya, terbukti bahwa pemakaian batubara lebih hemat. Dari segi peralatan mesin produksi campuran aspal panas (Asphalt Mixer Plant) dapat dioperasikan dengan menggunakan bahan bakar batubara yang harganya lebih murah dan performance mesin tersebut sama dengan apabila menggunakan bahan bakar kerosin. Riset ini dilakukan pada Mesin Pembuat Campuran Aspal Panas (Asphalt Mixer Plant) milik PT. Waskita Karya, merek Shin Sheng, type SAP 800 Batch, kapasitas 50 Ton/jam.
\end{abstract}

Kata kunci : Asphalt Mixer Plant, Burner Batubara, Kerosin, Batubara

\section{PENDAHULUAN}

Penelitian tentang studi perbandingan performance mesin pembuat campuran aspal panas (Agregat Mixer Plant) sangat penting karena apabila mesin pembuat campuran aspal panas menggunakan bahan bakar kerosin, biaya produksi sangat tinggi. Harga kerosin sangat fluktuaktif sangat tergantung negara lain terutama didaerah luar jawa, kerosin sangat langka dan sulit diperoleh. Sehingga waktu penyelesaian sering tidak sesuai rencana. Peraturan presiden no. 5 tahun 2006 tentang sasaran energi jangka panjang indonesia tahun 2000-2025, yang tujuannya mencari dan menggunakan energi alternatif lain yaitu, coal, gas, hydro, geothermal, biomass, angin, surya dan nuklir yang diharapkan biaya produksi lebih rendah. Fungsi mesin produksi campuran aspal panas untuk memproduksi campuran aspal panas dan sangat dibutuhkan untuk pembangunan jaringan angkutan darat di indonesia untuk keperluan pemeliharaan jalan-jalan beraspal yang sudah ada dan juga pembangunan jalan-jalan angkutan darat yang belum tersedia.

Permasalahan yang dihadapi pada mesin produksi campuran aspal panas terutama didaerah Kalimantan dan Sumatera adalah bahwa selama ini mesin produksi campuran aspal panas menggunakan kerosin. Sampai dengan saat ini ketersediaan bahan bakar kerosin tersebut semakin sulit diperoleh dan harganya semakin tinggi, sehingga biaya produksi menjadi tidak efisien lagi. Yang menjadi pertimbangan bagi penelitian ini adalah apakah mesin produksi campuran aspal 
panas dapat dioperasikan dengan menggunakan bahan bakar batubara yang harganya lebih murah, dan bagaimana performance mesin tersebut apabila dioperasikan menggunakan bahan bakar batubara dibandingkan dengan apabila menggunakan bahan bakar kerosin.

Penelitian ini dilakukan pada :

1. Mesin pembuat campuran aspal panas merek shin seng type SAP 800 Batch, kapasitan 50 Ton/jam.

2. Burner Batubara merk Hammada kapasitas 1,5 ton/jam.

3. Lokasi penelitian di proyek peningkatan jalan di kecamatan tayan, kabupaten Pontianak, Kalimantan Barat.

Tujuan utama penelitian ini adalah untuk mencari energi alternatif dalam hal ini batubara sebagai pengganti kerosin untuk bahan bakar pembuatan campuran aspal panas. Dengan menggunakan batubara sebagai pengganti kerosin, diharapkan dapat mengurangi ketergantungan kepada negara lain karena di Indonesia, batubara gampang diperoleh dan harganya relatif rendah.

Penggunaan batubara sebagai bahan bakar pembuat campuran aspal panas diperkirakan biayanya lebih murah dibandingkan dengan memakai kerosin, karena harga batubara lebih murah dan lebih gampang didapat daripada kerosin. Dengan dibuatnya tesis ini supaya bisa diketahui pemanfaatan batubara sebagai bahan bakar pembuat campuran aspal panas diharapkan mengurangi ketergantungan terhadap pemakaian kerosin dan biaya pembuat campuran aspal panas bisa lebih rendah.

Penelitian dilakukan dengan cara pengujian langsung setiap hari secara terus menerus selama 2 (dua) bulan. Tujuannya agar diperoleh data yang akurat.

Hal-hal yang diuji adalah :
1. Pemakaian kerosin untuk memproduksi per-ton campuran aspal panas.

2. Pemakaian batubara untuk memproduksi per-ton campuran aspal panas.

3. Suhu campuran aspal panas hasil pembakaran menggunakan kerosin.

4. Suhu campuran aspal panas hasil pembakaran menggunakan batubara.

\section{METODE PENELITIAN}

\section{Tempat dan Waktu Penelitian}

1. Tempat penelitian di proyek peningkatan jalan di kecamatan Tayan, kabupaten Pontianak, Kalimantan Barat.

2. Waktu pelaksanaan proyek 730 (Tujuh ratus tiga puluh) hari kalender terhitung mulai tanggal 30 Juli 2009 sampai dengan 29 Juli 2011.

3. Waktu pemeliharaan proyek 365 (Tiga ratus enam puluh lima) hari kalender terhitung mulai tanggal 29 Juli 2011 sampai dengan 28 Juli 2012.

4. Waktu penelitian 2 (dua) bulan terhitung mulai tanggal 01 Juli - 30 Juli 2010.

Material yang dibutuhkan untuk penelitian ini adalah sebagai berikut:

material sebagai berikut :

1. Asphalt Mixer Plant, merk Shin Sheng, type SAP 800 Batch, kapasitas 50 ton/jam

2. Burner Batubara merk Hammada, kapasitas 1,5 ton/jam

3. Whell Loader merk Komatsu, WA180 Genset merk Cummins, kapasitas $250 \mathrm{Kva}$

4. Truck scale kapasitas 80 ton

5. Thermometer $0-573{ }^{\circ} \mathrm{K}$

6. Aspal Cement 60/70 
7. Kerosin

8. Batu Bara 25,080 - 25,916 K. joule $/ \mathrm{kg}$

9. Agregat (batu pecah) ukuran 6-24 $\mathrm{mm}$

10. Abu batu

11. Pasir

12. Solar

\section{HASIL DAN PEMBAHASAN}

\section{Proses Pembakaran Burner Menggunakan Kerosin}

\section{Viscositas kerosin dan LSHS (Low Sulphur} Heavy Stok) meningkat dengan berkurangnya suhu yang dapat menyulitkan pemompaan minyak. Pada suhu ambeien yang rendah (dibawah $298{ }^{\circ} \mathrm{K}$ ), kerosin tidak dapat dipompa dengan mudah.

Untuk mencegah terjadinya hal ini, dilakukan pemanasan awal kerosin dengan dua cara :

- Memanaskan seluruh tangki kerosin dengan menempatkan kumparan steam di bagian bawah tangki, yang keseluruhannya diisolasi.

- Kerosin dapat juga dipanaskan pada saat dialirkan dengan menggunakan pemanas yang mengalir. Untuk mengurangi kebutuhan panas, tangki sebainya diisolasi.

Pemanasan seluruh tangki diperlukan jika laju aliran cukup tinggi, sehingga penggunaan pemanas yang mengalir tidak mencukupi, jika menggunakan pemanas yang mengalir, dilakukan pada saat kerosin keluar dari tangki sampai pada suhu pemompaan. Pemanas mengalir pada dasarnya merupakan sebuah penukar panas dengan steam atau listrik sebagai medianya.

Burner kerosin yang dipergunakan pada Asphalt Mixer Plant, pemanasan dilakukan di seluruh tangki kerosin. Kerosin dari tangki dialirkan melalui pipa menuju burner. Ketika hampir memasuki burner, kerosin diberi aliran udara bertekanan 10 (sepuluh) bar atau lebih dengan menggunakan compressor udara dan dialirkan ke burner. Di burner, kerosin dikabutkan dan dibakar. Panas (api) dari hasil pembakaran kerosin disemprotkan kedalam dryer untuk memanaskan batu pecah, abu batu dan pasir yang akan dipakai untuk campuran aspal panas.

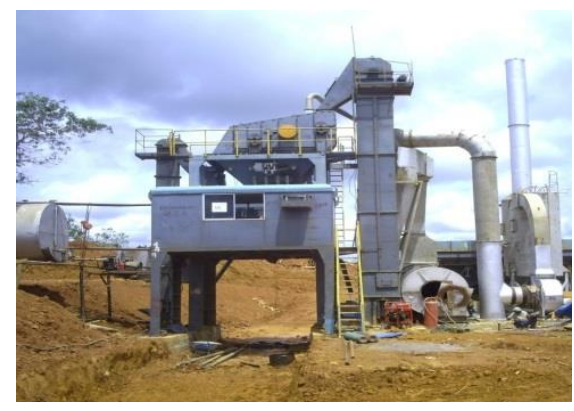

Gambar 1. Asphalt Mixer Plant

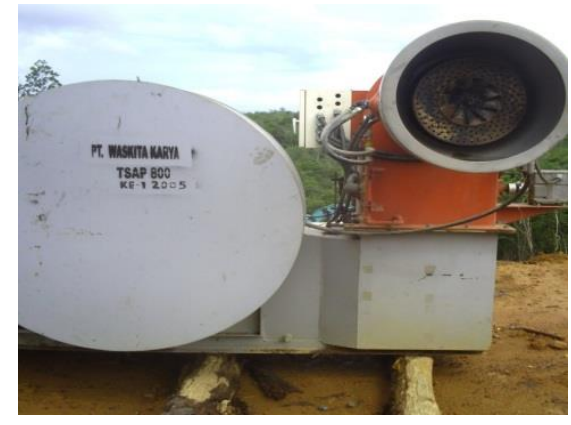

Gambar 2. Burner Kerosin

\section{Proses Pembakaran Burner Menggunakan Batubara}

Ukuran batubara yang benar merupakan salah satu kunci yang menjamin pembakaran yang efisien. Ukuran batubara yang tepat, sesuai dengan system pembakaran yang digunakan dapat membantu pembakaran, mengurangi kehilangan abu dan efisiensi pembakaran yang lebih baik. Ukuran batubara diperkecil dengan penggilingan / crushing dan penghancuran / pulverizing.

Cara pembakaran burner batubara yang digunakan pada Asphalt Mixer Plant mirip dengan Sistem Pressurized Fluidized Bed Combustion (PFBC). 
Batubara kering ukuran maksimum 5 (lima) centimeter dimasukkan ke hopper dengan memakai whell loader. Dari hopper, batubara dibawa oleh screw conveyor menuju coal crusher untuk dipecah. Keluar dari coal crusher, ukuran batubara menjadi maksimum 1 (satu) centimeter. Batubara kemudian masuk silo dengan menggunakan lifter. Dari silo, batubara masuk ke Pulverizer dipecah menjadi abu. Abu batubara yang keluar dari Pulverizer diberi aliran udara bertekanan 10 (sepuluh) bar atau lebih dengan menggunakan compressor udara dan dialirkan ke burner. Abu batubara keluar dari burner dan dibakar. Panas (api) dari hasil pembakaran abu batubara disemprotkan kedalam dryer untuk memanaskan batu pecah, abu batu dan pasir yang akan dipakai untuk campuran aspal panas.

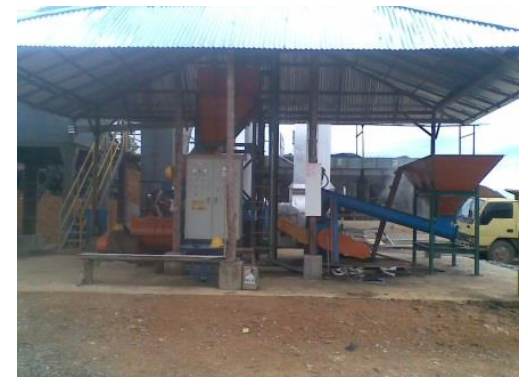

Gambar 3. Lay-out Burner Batubara

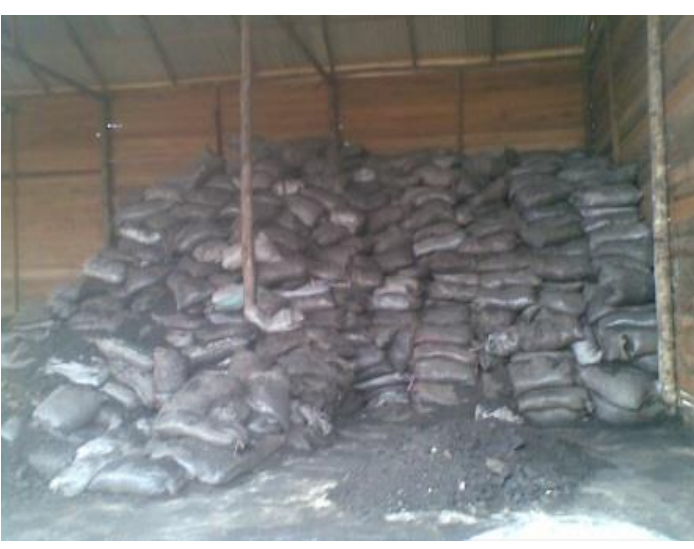

Gambar 4. Batubara

Penghematan Biaya Produksi Campuran Aspal Panas Apabila Bahan Bakar Kerosin Diganti Dengan Batubara adalah sebesar Rp. 109.096,-/ton. Terlihat pada table 1 dan 2:

Tabel 1. Biaya Produksi Campuran Aspal Panas Menggunakan Bahan Bakar Kerosin Bulan Juni 2010

\begin{tabular}{|c|c|c|c|c|c|c|c|c|c|c|c|}
\hline \multirow[t]{2}{*}{ No } & \multirow[t]{2}{*}{ Tanggal } & \multirow{2}{*}{$\begin{array}{c}\text { Hasil } \\
\text { Produksi } \\
\text { (Ton) }\end{array}$} & \multicolumn{2}{|c|}{ Sewa Alat } & \multicolumn{2}{|c|}{$\begin{array}{c}\text { Material Tidak } \\
\text { Termasuk Kerosin }\end{array}$} & \multicolumn{2}{|c|}{ Gaji Karyawan } & \multicolumn{2}{|c|}{$\begin{array}{c}\text { Kerosin } \\
\text { Rp. } 7.500,-/ \operatorname{ltr}\end{array}$} & \multirow{2}{*}{$\begin{array}{l}\text { Biaya Total } \\
\text { (Rp.) }\end{array}$} \\
\hline & & & (Rp./ton) & (Rp.) & (Rp./ton) & (Rp.) & (Rp./ton) & (Rp.) & $(\mathrm{Kg})$ & (Rp.) & \\
\hline 1 & 9 & 234 & 11,250 & $2,632,500$ & 454,283 & $106,302,222$ & 2,892 & 676,728 & 4,212 & $31,590,000$ & $141,201,450$ \\
\hline 2 & 10 & 288 & 11,250 & $3,240,000$ & 454,283 & $130,833,504$ & 2,892 & 832,896 & 5,472 & $41,040,000$ & $175,946,400$ \\
\hline 3 & 11 & 270 & 11,250 & $3,037,500$ & 454,283 & $122,656,410$ & 2,892 & 780,840 & 5,130 & $38,475,000$ & $164,949,750$ \\
\hline 4 & 12 & 252 & 11,250 & $2,835,000$ & 454,283 & $114,479,316$ & 2,892 & 728,784 & 5,040 & $37,800,000$ & $155,843,100$ \\
\hline 5 & 13 & 234 & 11,250 & $2,632,500$ & 454,283 & $106,302,222$ & 2,892 & 676,728 & 4,446 & $33,345,000$ & $142,956,450$ \\
\hline 6 & 14 & 288 & 11,250 & $3,240,000$ & 454,283 & $130,833,504$ & 2,892 & 832,896 & 4,896 & $36,720,000$ & $171,626,400$ \\
\hline 7 & 15 & 306 & 11,250 & $3,442,500$ & 454,283 & $139,010,598$ & 2,892 & 884,952 & 5,508 & $41,310,000$ & $184,648,050$ \\
\hline 8 & 16 & 216 & 11,250 & $2,430,000$ & 454,283 & $98,125,128$ & 2,892 & 624,672 & 4,104 & $30,780,000$ & $131,959,800$ \\
\hline 9 & 17 & 252 & 11,250 & $2,835,000$ & 454,283 & $114,479,316$ & 2,892 & 728,784 & 5,040 & $37,800,000$ & $155,843,100$ \\
\hline 10 & 18 & 324 & 11,250 & $3,645,000$ & 454,283 & $147,187,692$ & 2,892 & 937,008 & 6,480 & $48,600,000$ & $200,369,700$ \\
\hline 11 & 19 & 270 & 11,250 & $3,037,500$ & 454,283 & $122,656,410$ & 2,892 & 780,840 & 5,130 & $38,475,000$ & $164,949,750$ \\
\hline 12 & 20 & 162 & 11,250 & $1,822,500$ & 454,283 & $73,593,846$ & 2,892 & 468,504 & 2,916 & $21,870,000$ & $97,754,850$ \\
\hline 13 & 21 & 198 & 11,250 & $2,227,500$ & 454,283 & $89,948,034$ & 2,892 & 572,616 & 3,564 & $26,730,000$ & $119,478,150$ \\
\hline 14 & 22 & 108 & 11,250 & $1,215,000$ & 454,283 & $49,062,564$ & 2,892 & 312,336 & 2,160 & $16,200,000$ & $66,789,900$ \\
\hline 15 & 23 & 162 & 11,250 & $1,822,500$ & 454,283 & $73,593,846$ & 2,892 & 468,504 & 3,078 & $23,085,000$ & $98,969,850$ \\
\hline 16 & 24 & 180 & 11,250 & $2,025,000$ & 454,283 & $81,770,940$ & 2,892 & 520,560 & 3,600 & $27,000,000$ & $111,316,500$ \\
\hline 17 & 25 & - & - & - & - & - & - & - & - & - & - \\
\hline 18 & 26 & - & - & - & - & - & - & - & - & - & - \\
\hline 19 & 27 & 252 & 11,250 & $2,835,000$ & 454,283 & $114,479,316$ & 2,892 & 728,784 & 4,788 & $35,910,000$ & $153,953,100$ \\
\hline 20 & 28 & 216 & 11,250 & $2,430,000$ & 454,283 & $98,125,128$ & 2,892 & 624,672 & 4,968 & $37,260,000$ & $138,439,800$ \\
\hline 21 & 29 & 144 & 11,250 & $1,620,000$ & 454,283 & $65,416,752$ & 2,892 & 416,448 & 3,600 & $27,000,000$ & $94,453,200$ \\
\hline \multicolumn{2}{|c|}{ JUMLAH } & & & $49,005,000$ & & $1,978,856,748$ & & $12,597,552$ & & $630,990,000$ & $2,671,449,300$ \\
\hline \multicolumn{11}{|c|}{$\begin{array}{l}\text { BIAYA RATA-RATA PER-TON CAMPURAN ASPAL } \\
\text { PANAS }\end{array}$} & 613,280 \\
\hline
\end{tabular}


Tabel 2. Biaxa Produksi Campuran Aspal Panas Menggunakan Bahan Bakar Kerosin

\begin{tabular}{|c|c|c|c|c|c|c|c|c|c|c|c|}
\hline \multirow{3}{*}{ No } & \multirow{3}{*}{ Tanggal } & \multirow{3}{*}{\begin{tabular}{|c} 
Hasil \\
Produlksi \\
(Ton) \\
\end{tabular}} & \multicolumn{8}{|c|}{ Bulan Juli 2010} & \multirow{3}{*}{$\begin{array}{l}\text { Biaxa Total } \\
\text { (Rp.) }\end{array}$} \\
\hline & & & \multicolumn{2}{|c|}{ Sewa Alat } & \multicolumn{2}{|c|}{$\begin{array}{c}\text { Material Tidak } \\
\text { Termasuk Kerosin }\end{array}$} & \multicolumn{2}{|c|}{ Gaji Karyawan } & \multicolumn{2}{|c|}{$\begin{array}{c}\text { Kerosin } \\
\text { Rp. } 7.500,-1 \text { tr }\end{array}$} & \\
\hline & & & (Rp./ton) & (Rp.) & (Rp./ton) & (Rp.) & (Rp//ton) & (Rp.) & $(\mathrm{Kg})$ & (Rp.) & \\
\hline 1 & 5 & 252 & 14,250 & $3,591,000$ & 454,283 & $114,479,316$ & 3,203 & 807,156 & 6,048 & $7,862,400$ & $126,739,872$ \\
\hline 2 & 6 & 270 & 14,250 & $3,847,500$ & 454,283 & $122,656,410$ & 3,203 & 864,810 & 6,750 & $8,775,000$ & $136,143,720$ \\
\hline 3 & 7 & 234 & 14,250 & $3,334,500$ & 454,283 & $106,302,222$ & 3,203 & 749,502 & 5,382 & $6,996,600$ & $117,382,824$ \\
\hline 4 & 8 & 288 & 14,250 & $4,104,000$ & 454,283 & $130,833,504$ & 3,203 & 922,464 & 6,624 & $8,611,200$ & $144,471,168$ \\
\hline 5 & 9 & 270 & 14,250 & $3,847,500$ & 454,283 & $122,656,410$ & 3,203 & 864,810 & 6,750 & $8,775,000$ & $136,143,720$ \\
\hline 6 & 10 & 324 & 14,250 & $4,617,000$ & 454,283 & $147,187,692$ & 3,203 & $1,037,772$ & 8,424 & $10,951,200$ & $163,793,664$ \\
\hline 7 & 11 & 288 & 14,250 & $4,104,000$ & 454,283 & $130,833,504$ & 3,203 & 922,464 & 6,912 & $8,985,600$ & $144,845,568$ \\
\hline 8 & 12 & 234 & 14,250 & $3,334,500$ & 454,283 & $106,302,222$ & 3,203 & 749,502 & 5,850 & $7,605,000$ & $117,991,224$ \\
\hline 9 & 13 & 252 & 14,250 & $3,591,000$ & 454,283 & $114,479,316$ & 3,203 & 807,156 & 6,048 & $7,862,400$ & $126,739,872$ \\
\hline 10 & 14 & 324 & 14,250 & $4,617,000$ & 454,283 & $147,187,692$ & 3,203 & $1,037,772$ & 8,424 & $10,951,200$ & $163,793,664$ \\
\hline 11 & 15 & 162 & 14,250 & $2,308,500$ & 454,283 & $73,593,846$ & 3,203 & 518,886 & 3,888 & $5,054,400$ & $81,475,632$ \\
\hline 12 & 16 & 216 & 14,250 & $3,078,000$ & 454,283 & $98,125,128$ & 3,203 & 691,848 & 5,616 & $7,300,800$ & $109,195,776$ \\
\hline 13 & 17 & 198 & 14,250 & $2,821,500$ & 454,283 & $89,948,034$ & 3,203 & 634,194 & 5,148 & $6,692,400$ & $100,096,128$ \\
\hline 14 & 18 & 162 & 14,250 & $2,308,500$ & 454,283 & $73,593,846$ & 3,203 & 518,886 & 3,888 & $5,054,400$ & $81,475,632$ \\
\hline 15 & 19 & \begin{tabular}{|l|}
180 \\
\end{tabular} & 14,250 & $2,565,000$ & 454,283 & $81,770,940$ & 3,203 & 576,540 & 4,680 & $6,084,000$ & $90,996,480$ \\
\hline 16 & 20 & 216 & 14,250 & $3,078,000$ & 454,283 & $98,125,128$ & 3,203 & 691,848 & 5,832 & $7,581,600$ & $109,476,576$ \\
\hline 17 & 21 & - & - & & - & - & - & - & - & - & - \\
\hline 18 & 22 & 270 & 14,250 & $3,847,500$ & 454,283 & $122,656,410$ & 3,203 & 864,810 & 7,020 & $9,126,000$ & $136,494,720$ \\
\hline 19 & 23 & 288 & 14,250 & $4,104,000$ & 454,283 & $130,833,504$ & 3,203 & 922,464 & 6,912 & $8,985,600$ & $144,845,568$ \\
\hline 20 & 24 & 252 & 14,250 & $3,591,000$ & 454,283 & $114,479,316$ & 3,203 & 807,156 & 6,300 & $8,190,000$ & $127,067,472$ \\
\hline 21 & 25 & 306 & 14,250 & $4,360,500$ & 454,283 & $139,010,598$ & 3,203 & 980,118 & 7,956 & $10,342,800$ & $154,694,016$ \\
\hline JUM & ILAH & & 4,986 & & & & & & & & $161,787,600$ \\
\hline \multicolumn{11}{|c|}{$\begin{array}{l}\text { BLAYA RATA-RATA PER-TON CAMPURAN ASPAL } \\
\text { PANAS }\end{array}$} & 613,280 \\
\hline
\end{tabular}

\section{KESIMPULAN}

Dari hasil penelitian, dapat disimpulkan sebagai berikut :

1. Pemakaian kerosin rata-rata untuk memproduksi per-ton campuran aspal panas sebesar 19.47 (Sembilan belas koma empat tujuh) liter.

2. Pemakaian batubara rata-rata untuk memproduksi per-ton campuran aspal panas sebesar 24.95 (Dua puluh empat koma sembilan lima) $\mathrm{kg}$.

3. Temperatur rata-rata campuran aspal panas apabila menggunakan bahan bakar kerosin sebesar 417.76 (Empat ratus tujuh belas koma tujuh enam) ${ }^{\circ} \mathrm{K}$.

4. Temperatur rata-rata campuran aspal panas apabila menggunakan bahan bakar batubara sebesar 412.61 (Empat ratus dua belas koma enam satu) ${ }^{\circ} \mathrm{K}$.

5. Biaya rata-rata untuk memproduksi per-ton campuran aspal panas dengan menggunakan bahan bakar kerosin sebesar Rp. 613,280,- (Enam ratus tiga belas ribu dua ratus delapan puluh rupiah).

6. Biaya rata-rata untuk memproduksi per-ton campuran aspal panas dengan menggunakan bahan bakar batubara sebesar Rp. 504,184,(Lima ratus empat ribu seratus delapan puluh empat rupiah).

7. Penghematan biaya rata-raa produksi per-ton campuran aspal panas apabila bahan bakar kerosin diganti dengan batubara sebesar Rp. 109,096,000,- (Seratus sembilan ribu sembilan puluh enam rupiah).

8. Mutu campuran aspal panas masih sesuai spesifikasi yang diinginkan apabila bahan bakar kerosin diganti dengan batubara.

\section{DAFTAR PUSTAKA}

[1] Departemen Pekerjaan Umum, 2005. Spesifikasi Pekerjaan Peningkatan Jalan. Cetakan Ke-2. Jakarta.

[2] Departemen Permukiman dan Prasarana Wilayah Direktorat 
Jenderal Prasarana Wilayah, 2002. Manual Pekerjaan

Campuran Beraspal Panas. Jakarta.

[3] Muchidin, 2006. Pengendalian Mutu Dalam Industri Batubara. Bandung.

[4] PT. Hamada, 2006. Manual Burner Batubara. Jakarta.

[5] PT. Komatsu, 1992. Spesifications And Application Handook. Edition 15. Tokyo, Japan.

[6] PT. Trakindo Utama, 1994. Caterpillar Performance Handbook. Illinois, USA.

[7] PT. Trakindo Utama, 2004. Manual Asphalt Mixer Plant. Jakarta.

[8] PT. Waskita Karya, 2003. Manual Peralatan. Jakarta.

[9] Sukandarrumidi, 2006. Batubara dan Pemanfaatannya. Jogjakarta. 